\title{
Factors That Influence Relationships In Self-Managed Work Teams
}

Rick Tallman, University of Northern British Columbia, Canada

\begin{abstract}
Leaders and members have different roles in self-managed work teams. This paper examines the extent to which specific characteristics in the other relates to leaders and members perception of relationship quality. The results indicate that members' values of fairness and honesty, their negative affective disposition, and their self-management ability were related to leaders' perceptions of the quality of the relationship. From the member's perspective the only significant predictor of the quality of the relationship was the leader's task ability. The characteristics of members and leaders that relate to the respective leader and member ratings of relationship quality appear to relate to their role enactment.
\end{abstract}

Keywords: Self-Managed Work Teams; Leader-Member Exchange; Values; Affect; Ability

\section{INTRODUCTION}

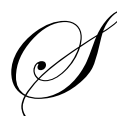

elf-managed work teams (SMWT's) have become more common as many organizations are using SMWT's in at least a portion of their operations (Erez, LePine \& Elms, 2002). SMWT's are seen as both task and social groups within organizations. Individual members are assigned task roles, but as a group, the team needs to be composed of members who have the requisite knowledge, skills and abilities to perform the work. Members also perform socio-emotional roles that help structure relationships and fulfill the social and emotional needs of members (Stewart, Manz \& Sims, 1999). Team member characteristics that enhance both intragroup relations and the ability of the team to reach its goals are important to the success of teams.

Leader-Member Exchange (LMX) theory indicates that leaders and members form differential relationships. Factors such as liking, ability or personal dispositions influence the quality of the dyadic relationship between leaders and members (Harris, Harris, \& Eplion, 2007; Liden, Wayne \& Stilwell, 1993; Graen \& Scandura, 1987). Although LMX theory was developed and tested based on traditional leader/member roles, it is suggestive that the relationship between leaders and members in SMWT's may be affected by the characteristics of the other. To-date this aspect of SMWT interactions has not been addressed.

The purpose of this study is to examine the influence of leaders' and members' abilities, work values and affective disposition on the development of the quality of the relationship between leaders and members and to determine if different sets of leader and member characteristics influence the relationship.

\section{LITERATURE REVIEW}

\section{Member and Leader Characteristics}

Both the SMWT and group behaviour literature indicate that the ability of group members to perform the task is an important aspect of successful teams. Two task ability characteristics are suggested by Stewart, Manz \& Sims (1999). The first is the specific ability to complete the task. The second is self-management skills. Selfmanagement skills are important in SMWT's as traditional supervision of member activities does not exist. LMX research has found that the ability to perform and complete unstructured tasks is an important determinant of the quality of the relationship between leaders and members (Day \& Crain, 1992). It would be expected that the ability to perform the task and to manage oneself would significantly influence the quality of the relationship between 
leaders and members of SMWT's.

Hypothesis 1a. Leader's perceived relationship quality with SMWT members will be related to the members' specific and self-management abilities.

Hypothesis 1b. Member's perceived relationship quality with SMWT leaders will be related to the leaders' specific and self-management abilities.

Leaders' values have been shown to affect perceptions of leader-member relations (Mahsud, Yukl \& Prussia, 2010). It can be expected that the values held by both leaders and members will affect their perceived relationship quality with each other as values guide behaviour choices (Rokeach, 1973). Ravlin and Meglino (1987) have suggested four work values that relate to behaviour. These are achievement, concern for others, fairness and honesty.

Values diversity affects team conflict (Klein, Knight, Ziegert, Lim and Saltz, 2011) and one of the critical issues in SMWT's is conflict resolution (Stewart et al., 1999). Conflict may be a particular concern in SMWT's because neither the team members nor the team leader have the power to directly resolve conflict. As managing conflict is typically a team leader role, team leaders are likely to value team members who provide socio-emotional inputs that assist in the enactment of this role. Team members with high concern for others and fairness values are likely to assist in this regard. As a result, team leaders can be expected to develop higher quality relationships with members holding these values. As other team members may provide the inputs to resolve conflict, there may not be a significant relationship between leaders' values of concern for others and fairness and members perceptions of the quality of the relationship between themselves and the leader.

SMWT's are social groups. People with a high achievement value are likely to be less social in nature on a team setting. Their desire to take personal responsibility for problems, to differentiate themselves from others and to feel that success has come from their actions may make them difficult to work with (McClelland, 1961) in the highly interdependent environment of SMWT's. Leaders and members with a high achievement value may tend to create team conflict as they strive to succeed. They are likely to be frustrated in an environment where they are highly dependent on others in the group for success. They may attempt to take ownership of problems and complete them on their own or become too directive of others. This value in leaders or members is likely to strain the relationship between each other.

Leaders and members of SMWT's should appreciate high honesty values in each other. Both should appreciate each other taking responsibility for their actions. This value should facilitate the functioning of the group (helping leaders enact their roles) and the completion of the task (of interest to members). High honesty values in leaders and members are likely to result in higher quality relations with the other.

Hypothesis 2a. There will be a positive relationship between leaders' perceptions of the quality of the relationship with members and members' values of concern for others, fairness and honesty.

Hypothesis 2b. There will be a negative relationship between leaders' perceptions of the quality of the relationship with members and members' value of achievement.

Hypothesis 2c. There will be an negative relationship between members' perceptions of the quality of the relationship with leaders and leaders' value of achievement.

Hypothesis 2d. There will be a positive relationship between members' perceptions of the quality of the relationship with leaders and leaders' values of honesty.

Positive Affectivity (PA) and Negative Affectivity (NA) have been shown to be robust descriptors of mood and to represent the major dimensions of emotional experience (Watson, 1988). They reflect people's emotional state and the manner in which people respond to their environment. People with a high PA mood would tend to be happy, optimistic and excited about their world. Positive affectivity has been found to promote helpfulness (Isen \& 
Levin, 1972) and increase pro-social behaviour (George, 1992). High NA people are more inclined to dwell on the negative side of themselves and their situation (Weiss \& Cropanzano, 1996). Negative affectivity has been found to significantly predict withdrawal behaviour and job dissatisfaction (George, 1992; Judge, 1992).

Affective disposition of leaders and members should play a significant role in the functioning of, and relationships in, SMWT's. Leaders or members high in PA should be preferred in the interdependent and social environment of SMWT's as they are likely to be more willing to contribute to the group tasks, more helpful to other group members and reduce intra-group conflict. This attribute would facilitate both the leader role and the completion of the task. Leaders or members high in NA, on the other hand, are likely to be disliked in SMWT's as they may not contribute fully on team tasks or they may be a negative influence on the social aspects of the team and the group processes. Glaso \& Einarsen (2006) found that affective experiences during leader and member interactions affect their relationship.

Hypothesis 3a. Member PA will be directly, and member NA will be inversely, related to leaders' ratings of relationship quality with members in SMWT's.

Hypothesis 3b. Leader PA will be directly, and leader NA will be inversely, related to members' ratings of relationship quality with leaders in SMWT's.

\section{METHOD}

\section{Participants}

The subjects for this study were students enrolled in five classes. A total of 198 students participated in this study. The demographics of the students were as follows: $53 \%$ were female; the average age was 22.5 years; and they averaged 3.3 years of university study.

The students were randomly assigned to groups of three to six people, in each of the courses, in order to participate in extensive group work throughout the term. Student work groups were appropriate subjects for this study because they closely resemble self-managed work teams. They completed an entire piece of work involving interdependent tasks over which they have substantial autonomy. In addition, the leaders had no authority over the group members. There were a total of 44 groups and leaders were randomly assigned the leader role. All students in a group were essentially equal in terms of the contribution they could make to the groups' work and their ability to enforce cooperation and compliance. Leaders were given the additional tasks of being the prime contact between the groups and the instructor, and organizing and facilitating task completion. Throughout the term, the groups participated in class to solve problems directly related to the material being presented in their course of study. These problems were time limited and graded, and the marks used as part of the students' final course grade making task performance important to them.

Data on the students' individual work values, affective disposition and grade point average was collected at the start of the term. Data on the LMX relationship was collected at the end of the term. Student grades for the course were collected at the completion of the term.

\section{Measures}

Relationship Quality. Relationship quality was assessed using the seven (7) item, five-point scale Leader-Member Exchange measurement instrument (Scandura \& Graen, 1984). The Cronbach's alpha reliability coefficients for the LMX ratings for this study were for members .93 and for leaders .93.

Work Values. The work values measure used for this study was the Comparative Emphasis Scale developed by Ravlin and Meglino (1987). This scale is designed to measure four general workplace values: achievement/working hard; concern for/helping others; fairness; and honesty/integrity. It uses a forced choice format where each value statement is paired against a statement representing a different value. This format eliminates the problem of the social desirability of values inflating the scores one would find on a Likert-type instrument. There are twenty-four 
pairs of statements so that each value can be chosen as many as twelve times although the total of all values chosen can only equal twenty-four. The number of times a value is chosen is added and the resulting scores indicate the degree to which various values are held.

Affective Disposition. The affective disposition measure used in this study was the Positive and Negative Affect Scale (PANAS) (Watson, Clark \& Tellegen, 1988). This scale involves 10 adjectives that describe positive (PA), and 10 adjectives that describe negative (NA), feelings and emotions, all rated on a 5 point scale. These adjectives were based on how they felt in general over the past year.

Ability. The student's grade point average (GPA), as reported at the start of the term by the student, and marks for the course were used as measures of ability. As the students were completing tasks that related to the course of study, course marks provide a good measure of their specific task ability to do the tasks assigned. Students' grade point average was used as a proxy for self-management ability as good self-management is likely needed to achieve a high grade point average.

\section{RESULTS}

We found that some of the group leaders, in rating their relationship with group members, did not distinguish between members on their ratings. Graen and Scandura (1987) have noted that this is a common problem with supervisors' LMX ratings of their group members as supervisors tend to not want to acknowledge that they discriminate between members. Since we were interested in differentiated groups, we excluded data from leaders where differentiation failed to occur. The means, standard deviations and correlations between the study variables are shown in Table 1. The relationship between leaders' rating of the relationship and members' characteristics was also examined using regression analysis as shown in Table 2.

\section{Leader Relationship Ratings versus Member Characteristics}

It was hypothesized that leaders' relationship quality with SMWT members would be directly related to members' specific ability, self-management abilities, concern for others, fairness, honesty, and positive affectivity and inversely related to the members' achievement value and negative affectivity. As can be seen in table 1, leaders' ratings of the LMX relationship were significantly and directly correlated to members' fairness $(\mathrm{r}=.20)$, grade point average $(r=.23)$, course mark $(r=.20)$, and inversely related to negative affectivity $(r=-.26)$. In the regression analysis, leaders LMX ratings were significantly related to member fairness $(\beta=.378)$, honesty $(\beta=$ $.251)$, grade point average $(\beta=.224)$ and negative affectivity $(\beta=.233)$ as hypothesized. Hypotheses 1a , 2a and 3a were partially supported

Contrary to expectations, concern for others was negatively correlated $(r=-.23)$ to leaders' ratings of the quality of the relationship. Leaders' LMX ratings were not related to members' achievement values and positive affectivity in either the correlation analysis or the regression analysis.

Overall, this study found that member characteristics appear to influence leaders' perceptions of the quality of the relationship between themselves and team members. Members' values of fairness and honesty, their selfmanagement skills and their negative affective disposition combined to explain $23 \%$ of the variance in leaders' ratings of the quality of the relationship. 
Table 1.Correlation Matrix For LMX Ratings of the Relationship and Characteristics

\begin{tabular}{|c|c|c|c|c|c|c|c|c|c|c|c|c|}
\hline Variables & $\overline{\mathbf{M}}$ & SD & 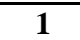 & 2 & 3 & 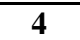 & 5 & $\overline{66}$ & 7 & $\overline{8}$ & 9 & 10 \\
\hline 1 LLMX & 25.1 & 5.42 & - & & & & & & & & & \\
\hline 2 Achievement & 5.89 & 2.58 & -.12 & - & & & & -.16 & $-.35 *$ & -.07 & .08 & -.07 \\
\hline 3 Concern for Others & 6.15 & 2.47 & $-.23 *$ & & - & & & -.08 & .16 & .05 & .13 & -.07 \\
\hline 4 Fairness & 5.54 & 2.12 & $.20 *$ & & & - & & -.05 & -.05 & $.25^{*}$ & $-.28 *$ & .02 \\
\hline 5 Honesty & 6.44 & 2.25 & .16 & & & & - & $.19 *$ & $.26^{*}$ & $-.29 *$ & .15 & .12 \\
\hline 6 GPA & 3.02 & .47 & $.23 *$ & .11 & -.03 & -.11 & .02 & - & $.55^{*}$ & -.16 & -.07 & .08 \\
\hline 7 Mark & 72.4 & 6.50 & $.20 *$ & .01 & -.03 & .04 & .00 & $.54 *$ & - & .02 & .05 & $.29 *$ \\
\hline $8 \mathrm{NA}$ & 20.0 & 5.11 & $-.26^{*}$ & .07 & -.11 & $.17 *$ & -.11 & -.04 & -.16 & - & -.32 & -.01 \\
\hline $9 \mathrm{PA}$ & 34.7 & 4.67 & -.10 & .10 & -.10 & .05 & -.06 & -.02 & -.01 & -.15 & - & .06 \\
\hline 10 MLMX & 26.3 & 5.44 & & & & & & & & & & - \\
\hline
\end{tabular}

* significant at $\mathrm{p}<.05$, note: The correlations below the diagonal are leader LMX ratings and member characteristics; the correlations above the diagonal are member LMX ratings and leader characteristics; LLMX and MLMX means respective leader and member LMX ratings

Table 2. Results of Multiple Regression Analysis for Ratings of Relationship Quality

\begin{tabular}{lccc}
\hline \hline \multicolumn{1}{c}{ Member Variables } & Leader LMX beta & Leader Variables & Member LMX beta \\
\hline \hline Achievement & .060 & Achievement & .033 \\
Concern & -.064 & Concern & -.118 \\
Fairness & $.378^{* *}$ & Fairness & .030 \\
Honesty & $.251^{*}$ & Honesty & .047 \\
GPA & $.224^{*}$ & GPA & -.117 \\
Mark & -.028 & Mark & $.288^{* *}$ \\
NA & $-.233^{*}$ & NA & -.016 \\
PA & -.111 & PA & .043 \\
F & $5.152^{* *}$ & & $10.237^{* *}$ \\
$\mathrm{R}^{2}$ & .230 & & .083 \\
Adjusted $\mathrm{R}^{2}$ & .185 & & .075 \\
\hline \hline
\end{tabular}

$* \mathrm{p}<.05, * * \mathrm{p}<.01$

\section{Member Relationship Ratings versus Leader Characteristics}

It was hypothesized that members' relationship quality with SMWT leaders would be directly related to leaders' specific and self-management abilities, leaders' honesty value and positive affectivity and inversely to leaders' achievement value and negative affectivity. A significant correlation was found for members' ratings of the quality of the relationship and leaders' class mark. No other leader variable had a significant correlation with members' ratings. Similarly in the regression analyses only leaders' class marks were related to members' ratings. All other leader variables were not related. These results partially support hypothesis $1 b$. Hypotheses $2 \mathrm{c}, 2 \mathrm{~d}$ and $3 \mathrm{~b}$ were not supported.

Overall, with the exception of the leaders' ability to perform the task, leaders' characteristics do not appear to influence members' ratings of the quality of their relationship with team leaders. Leaders' task ability only explained $8 \%$ of the variance in members' ratings of the relationship.

\section{DISCUSSION}

The current study examined the relationships between leader' and member' work values (achievement, concern for others, fairness and honesty), negative and positive affectivity, and ability (grade point average, and course mark) and leaders and members relationships. Two sets of hypotheses guided the study, one set dealing with leaders' ratings of members and the other, members' ratings of leaders. Both sets of hypotheses were partially supported. Members' values of fairness and honesty, their negative affective disposition, and their self-management ability were related to leaders' perceptions of the quality of the relationship. From the member's perspective the 
only significant predictor of the quality of the relationship was the leader's task ability.

An underlying premise of this study was that leaders had a broader role than did members in SMWT's. In SMWT's, leaders and members are expected to enact their roles. It was anticipated that, as a result of role differences, leaders and members would prefer different sets of characteristics in the other. This preference was measured through leaders and members' ratings of the quality of the relationship. In order to control for extraneous influencing variables, leaders and members were assigned to both their team and their role. In doing so, it ensured that the enactment of roles by leaders and members would be a prime determinant of each set of subjects' preferences for the others' characteristics. This study found clear differences in the characteristics leaders and members preferred in the other.

The role for leaders in this study was to facilitate their group in the completion of the assigned tasks and to contribute to the completion of the tasks. The member characteristics that were significant in this study are ones that affected the leader's ability to enact their role. Members who held high fairness and honesty values and who had high self-management abilities likely provided important socio-emotional inputs to the group. In addition to assisting with the completion of the tasks, these members presumably made the leaders' job easier. Members high in negative affectivity, on the other hand, were probably disruptive to the social nature of the group and may not have contributed equally to the completion of the task.

It is unclear why need for achievement and concern for others failed to be related to the ratings of the relationships. In all likelihood, it may be a result of the type measurement instrument employed. The forced choice nature of the instrument means that the four value variables are not independent of each other. This presents a dilemma for researchers who examine the impact of value variables on outcome variables. The nature of this instrument has the benefit of reducing the inflation of responses because of the social desirability of the values being examined but creates problems with the analysis and its interpretation. It is equally unclear why positive affectivity was not related to the relationship ratings. Previous research suggests that positive affectivity should contribute to the functioning of groups and completion of tasks

The classroom situation presented some interesting qualitative observations in that the classes were designed to teach effective team processes. In a number of the groups, leaders failed to differentiate widely between group members. This lack of differentiation may have been an artifact of norms, which dampened differentiated ratings. On the other hand, these data could indicate that, in team settings where team performance is directly related to the effectiveness of the team process, less differentiation may occur. While there may be natural tendencies for traditional leaders to differentiate between group members, the current emphasis on team processes may be leading to less differentiation. Leaders may be encouraged to recognize the diversity of skills within group members and may be asked to make the most effective use of all members' skills.

A number of deficiencies could be noted in the current study. The nature of the values scale, where subjects were asked to rate pairs of sentences, violated the independence assumption of the regression analyses and thus may have impacted the results. Future research should incorporate a scale with independent measurements. One could also question the generalizability of these results to natural field settings in traditional work environments. Care was taken to include as much group work as possible in the course with exercises, quizzes, and exams all dependent on the group process. However, it is important to note critical differences between the groups in the classroom and SMWT's. In the classroom groups, the success of the group had a direct impact on the success of the individual student in the course. Students who were concerned about their course mark may have exercised greater control over the group and the task than may normally occur in SMWT's. Self-interest may explain the significant relationship between the ability variables and relationship ratings. In a work setting, the success of the group may have greater relevance to the organization rather than to the individual. As a result, self-interest is less likely to operate as an intervening variable. In addition, no data was collected on inter-member relations. It would have been interesting to see if inter-member relations would add to or clarify the results of this study. As a last observation, the overall $\mathrm{R}^{2} \mathrm{~s}$ were rather low ( $8 \%$ to $23 \%$ ) which suggests the current study failed to identify a number of critical variables relevant to the relationships. 
In conclusion, these results advance the self-managed work team literature by demonstrating that leaders and members form relationships with each other on the basis of ability and personal characteristics. These factors were relevant to leaders' and members' performance and role enactment. These results suggest some possible future research. A replication in a work setting would be useful. It would be interesting to examine the interaction of personal characteristics of all self-managed work team members, relationships between them, and team performance. In addition, this study indicates there are a number of other variables that influence relationships in SMWT's. Exploratory research to discover what they are would be valuable to both the SMWT and the leadership literature.

\section{AUTHOR INFORMATION}

Rick Tallman, Ph.D. is an Associate Professor of Organizational Behaviour in The School of Business at the University of Northern British Columbia in Canada. He teaches Organizational Behaviour at the graduate and undergraduate level and Human Resources Management to undergraduates. His research interests include psychological contracts, teams, leadership, employee perceptions and workplace environments. Rick has extensive managerial experience having managed the operations in a variety of manufacturing organizations before joining academia. He has held positions from Supervisor to General Manager and utilizes that experience and knowledge in his teaching and research. E-mail: tallmanr@unbc.ca

\section{REFERENCES}

1. Day, D. and Crain, E. (1992). The role of affect and ability in initial exchange quality perceptions. Group \& Organization Management, 17(4), 380-397.

2. Erez, A., Lepine, J. and Elms, H., (2002). Effects of rotated leadership and peer evaluations on the functioning and effectiveness of self-managed team: a quasi-experiment. Personnel Psychology, 55, 929948.

3. George, J. (1992). The role of personality in organizational life: issues and evidence. Journal of Management, 18(2) 185-213.

4. Glaso, L. and Einarsen, S. (2006). Experienced affects in leader-subordinate relationships. Scandinavian Journal of Management, 22, 49-73.

5. Graen, G. and Scandura, T. (1987). Towards a psychology of dyadic organizing. Research in Organizational Behavior, 9, 175-208.

6. Harris, K., Harris, R. and Eplion, D. (2007). Personality, leader-member exchanges, and work outcomes. Journal of Behavioral and Applied Management, 8(2), 92-107.

7. Isen, A. and Levin, P. (1972). The effect of feeling good on helping: cookies and kindness. Journal of Personality and Social Psychology, 21, 384-388.

8. Judge, T. (1992). The Dispositional perspectives in human resources research. Research in Personnel and Human Resources Management, 10, 31-72.

9. Judge \& Chandler, 1991

10. Klein, K., Knight, A., Ziegert, J., Lim, B., and Saltz, J. (2011). When team members' values differ: the moderating role of team leadership. Organizational Behavior and Human Decision Processes, 114, 25-36.

11. Liden, R., Wayne, S., and Stilwell, D. (1993) A longitudinal study of the early development of leadermember exchanges. Journal of Applied Psychology, 78, 662-674.

12. Mahsud, R., Yukl, G. and Prussia, G. (2010). Leader empathy, ethical leadership, and relation-oriented behaviors as antecedents of leader-member exchange quality. Journal of Managerial Psychology, 25(6), 561-577.

13. McClelland, D. C. (1961). The Achieving Society. New York: Van Nostrand Reinhold.

14. Ravlin, E and Meglino, B. (1987). Effect of values on perception and decision making: a study of alternative work values measures. Journal of Applied Psychology, 72(4), 666-673.

15. Rokeach, M. (1973) The Nature of Human Values. New York: Collier MacMillan.

16. Scandura, T. and Graen, G. (1984) Moderating effects of initial leader-member exchange status on the effects of a leadership intervention. Journal of Applied Psychology, 69(3), 428-436.

17. Stewart, G., Manz, C. and Sims, H. (1999). Team Work and Group Dynamics, New York: J Wiley. 
18. Watson, D. (1988). The vicissitudes of mood measurement: Effects of varying descriptors, time frames, and response formats on measures of positive and negative affect. Journal of Personality and Social Psychology, 55, 128-141.

19. Watson, D., Clark, L. and Tellegen, A.. (1988) Development and validation of brief measures of positive and negative affect: the PANAS scales. Journal of Personality and Social Psychology, 54(6) 1063-1070.

20. Weiss, H. and Cropanzano, R. (1996). Affective events theory: a theoretical discussion of the structure, causes and consequences of affective experiences at work. Research in Organizational Behavior, 18, 1-74.

\section{NOTES}

